\title{
OPERATION BLUETONGUE: immigrants, nature and belonging
}

\author{
Transforming Cultures eJournal, \\ Vol. 5 No 1 June 2010 \\ http://epress.lib.uts.edu.au/journals/TfC
}

\section{Leandro Mendes}

\begin{abstract}
Leandro Mendes is an activist and educator who coordinated Operation Bluetongue, a program which addressed the interaction between recently arrived migrants and the natural environment in urban Sydney. This is an edited transcript of the talk he delivered to the Cities Nature Justice conference, December 2009, followed by questions and answers.
\end{abstract}

I would like to talk about a recent project, which was run through the Ethnic Communities Council. It was only funded for one year, but we hope it will be reactivated soon. I would like to take you through the journey right from the beginning to the show you how the ideas developed as it worked out and then what we can learn from it.

The program was called Operation Bluetongue. I know that sounds a little bit like some kind of CIA program but it's an environmental education program. Its main focus was to introduce new-arrival migrants and refugees to the concept of biodiversity and environmental education about Australia and to give them the opportunity to meet the original people, the Aboriginal people here in Australia. That was one of the main components of the program, which was developed within the Ethnic Communities Council and funded for one year by the Environmental Trust managed by the NSW Department of Environment, Climate Change and Water.

It is important to stress that this program was for new-arrival migrants and refugees. By new arrival, I mean the people who have arrived here within five or six years. Of course, I still feel like I'm a new arrival, even though I came over some time ago, so I needed to put a time frame to it. There are already some environmental programs which 
work with migrants at the moment, but they are with groups that have been here for twenty to thirty years. But this particular program was for people who had just arrived in Australia.

The way the program worked was that first of all, I would run a one hour workshop with migrant groups. Each one of these workshops contained people from many different ethnic groups - there was not only one group represented by each workshop but instead a mixture of people in each. These workshops gave us an opportunity to talk about the environment, biodiversity in Australia. I could mention the fact that Australia is a mega-diverse country, but I would also be talking about environmental problems in Australia. There is a concept sometimes that Australia is the land of plenty, so when people come to Australia they might have the idea that there is plenty of everything, that its a wealthy country, that its 'first world'. So I was always trying to mention the fact that there are environmental problems here, around issues such as water, loss of habitat, extinction of animals and things like that. And people have been very responsive to that.

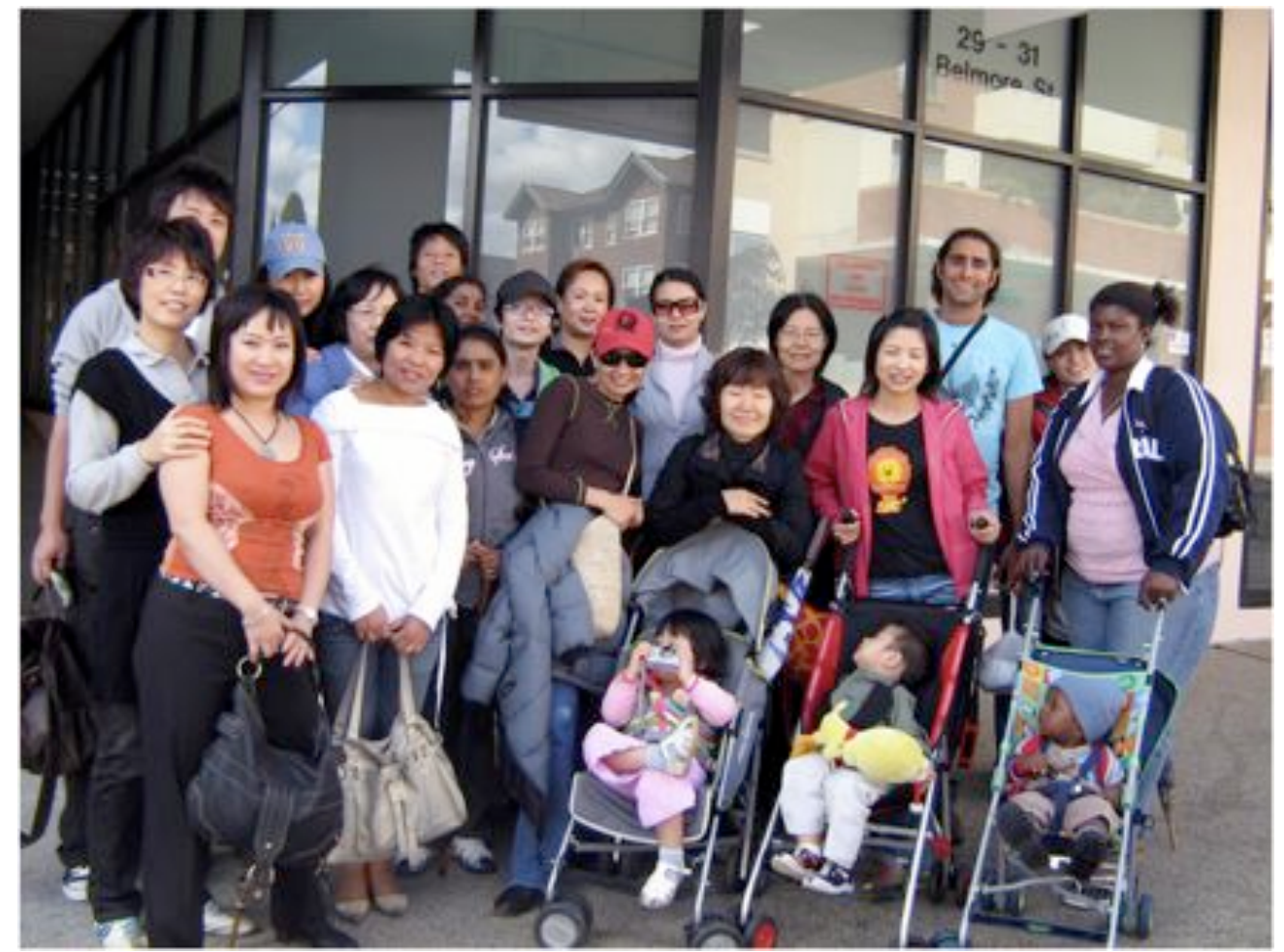

'Just back from our trip to Olympic Park.' A group from the Adult Migrant English Program, Burwood, taking part in Operation Bluetongue. Coordinator Leandro Mendes is in the back row on the right. 
Some of you have been through the experience of being a new arrival as a migrant, as I certainly did. When I started the program, my main concern was that when you're a new arrival, your priority obviously might not be the environment. You've just arrived in Australia, you don't know the language, you don't have a job, everything is completely different from where you originally come from. So you have a whole lot of other issues that you have to deal with, and environment may not be the top of your priority. But as the program progressed, it was amazing how strong the interest was from people - their interest to learn about and to be more familiar with the new environment that they were now in.

When I started the program my aim was to reach about a thousand people in one year, to have a thousand participants. By the end of one year and three months, I had had two and a half thousand people participate in the program. This is just to show you how strong that interest was. It's not only about the success of the program, I think that is less important than the amount of interest that's out there. People are really interested to learn, they're interested to become familiarised with the environment through the program.

So in this one hour workshop, I never used complicated technology because it's quite problematic, so often I took just pictures with me. Remember, these were just new arrivals so we needed to use very basic language. I brought a translator with me, from at least one of the languages people were using, so I was very aware of that. But after that one workshop, I invited them to come for a field trip. On the field trip a bus would come and pick them up. Transport seems to be a big issue with most people, because obviously you dealing with migrants with low income, so transportation is a big deal. When they knew the bus was coming, everyone was excited about it! So a bus would come and we would go to a local reserve. That also was a choice that we made: should we take them to a local reserve or maybe to a national park. I work throughout Sydney and there are a lot of amazing spots that people are not aware of, so finding somewhere close and local seemed important. More often than not people made comments like: 'I live three blocks from that reserve and I didn't even know that it existed.' We went to places such as Parramatta Lakes, which is a classic example where people live maybe four blocks away and didn't know such a place existed. 
So we take people to a local reserve, then on arrival they are welcomed by an Aboriginal person, and they had opportunity to have an Aboriginal cultural exchange, which might take place for around 40 minutes. Now because I work with various different Aboriginal people, each one of them has had their own input. Some people had a very artistic input on their presentation, some people are very political about it, so I respect that, I have always left up to them to say what they really want to say, you know, so it is an opportunity just for them. And the reason I had that was because I respect the Aboriginal connection to the land, and also because as a new arrival, that was my personal experience. I spoke with a lot of the participants on the program, to see what effect this had, and I asked them for feedback and evaluation. As a new arrival myself, when I first arrived here, the things I heard from the mainstream about Aboriginal people a lot of the time was very negative. So straight away I thought there was an opportunity for those two groups, that otherwise might not meet, to have the opportunity to meet. And that proved actually to be very, very successful. People often make a comment like: 'If I hadn't had this opportunity I probably wouldn't ever meet an Aboriginal person.' So, in itself, that was a really great outcome.

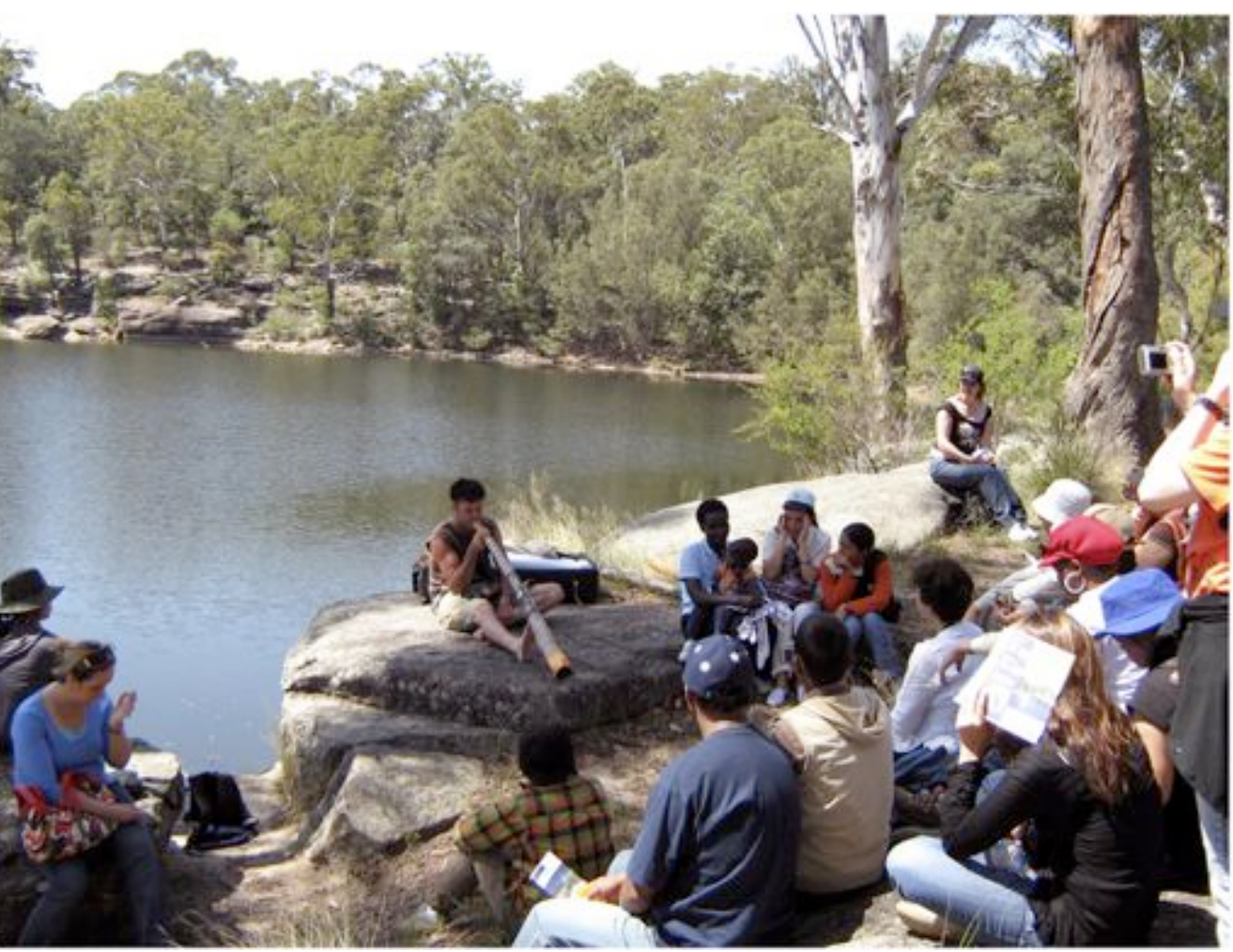

Cultural exchange, Parramatta River with an Operation Bluetongue group.

So after that forty minutes introduction, we would go for a bush walk and after that we have lunch together, so we would be socialising by sharing food - migrants are very 
much into that. Then after that we would have an animal display, with real live animals, all from the Sydney area. The people had an opportunity to touch and take photos. This was aimed at breaking down the misconceptions they might have about wildlife in Australia. I like it that sometimes movies like Crocodile Dundee showed Australia to the world, but it made a lot of people scared. So when people come here they had a lot of fears about dangerous snakes and poisonous spiders and all that. So that was a good opportunity for people maybe to break those fears. Often in that one hour workshop I would say, 'Yeah there are snakes out there, but that shouldn't stop you going into nature, that doesn't stop you to enjoying the Australian environment.'

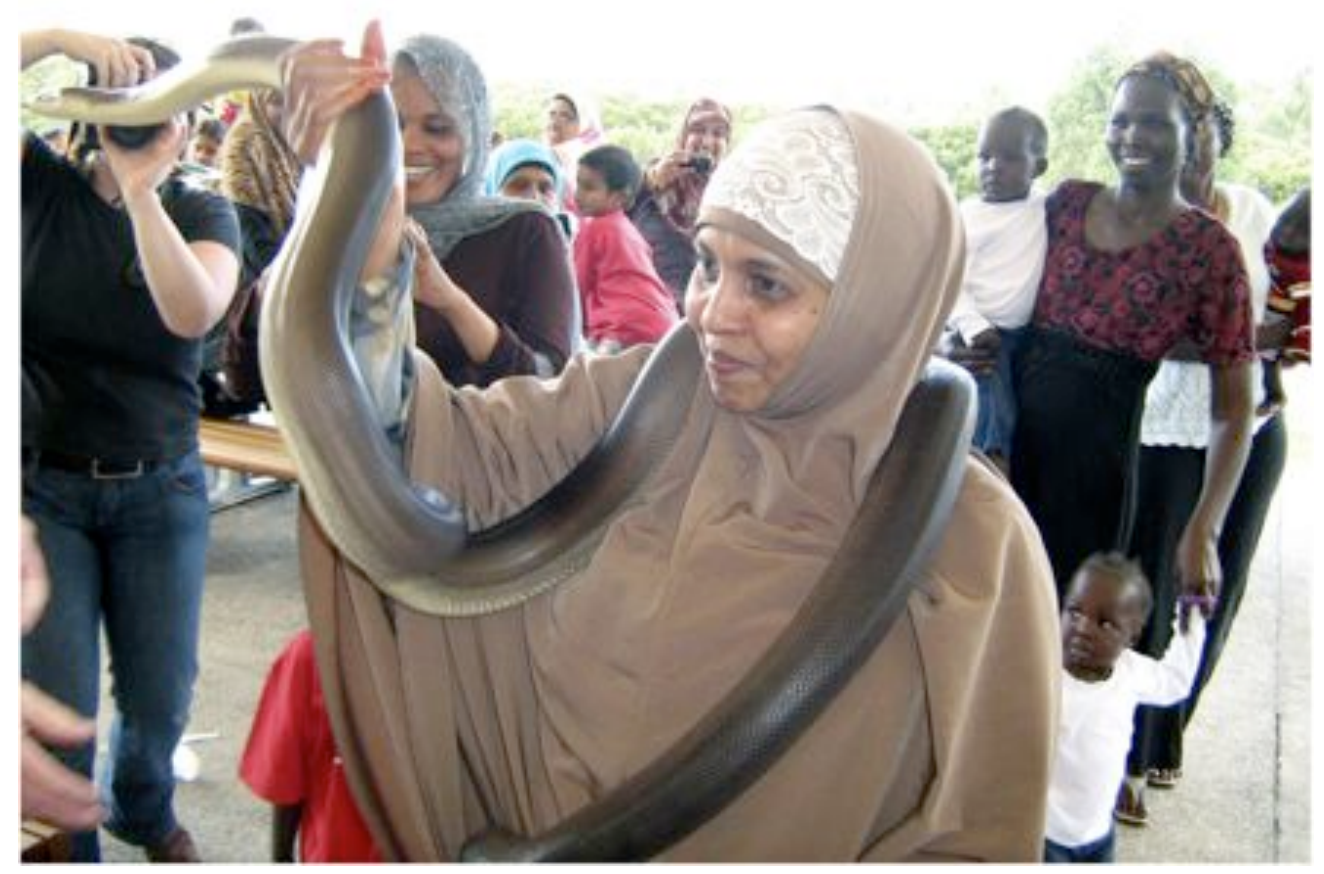

Women's African Refugee group, Olympic Park

I had 29 workshop and 22 field trips. I was aiming for a certain geographic region to have councils that supported the program, not financially but in kind contribution. In the beginning, this geographic spread was Parramatta, Bankstown, Blacktown and Auburn. So I was aiming to work only in those four areas. By the end of the program, the basic geographic spread had expanded from those first four - Auburn, Blacktown, Bankstown and Parramatta - to include Mount Druitt, Burwood, Fairfield, Cabramatta, Eastwood, Rockdale, Surry Hills, Sutherland, Hurstville, Randwick, Canley Valley and Meadowbank. That's how many areas Operation Bluetongue worked in across Sydney. 
The interest was being spread by word of mouth, with people who had been on it saying things like Ngan Doan, from the St George and Sutherland Community College:

What a wonderful excursion! It gives me a lot of knowledge about Australian trees, animals and especially about Aboriginal culture.

Another person, Julia Linh, a student from ACL, in Cabramatta, said:

Through the excursion we learn more about the nature around us and realise the environment's importance to our life.

In the end, I had invitations from all over the place, I just could not go everywhere at the same time. That's just to give an idea the need that's out there.

I'd like to move on from the environmental study, to look at the social side because that's also been my background. Although you might start with something like environmental education, or whatever you decided to do, after working with so many group, with so many people, they actually get a great deal of the social element to it, which is so important for them. And it's so important for us to recognise.

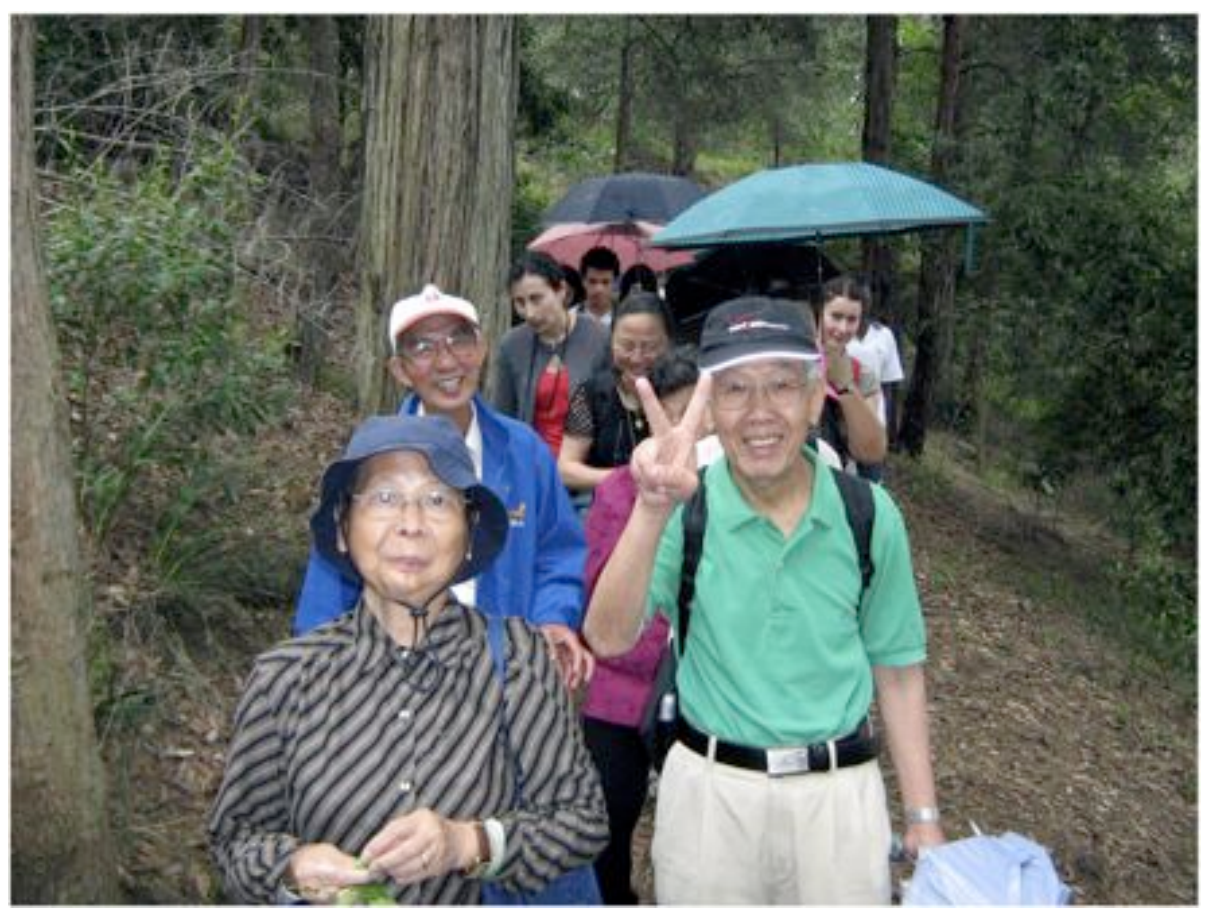

A Bushwalk along the Parramatta River

One issue is that a lot of groups complain that they usually go on outings by themselves, with members of their own community, so they have no idea of a wider community. The Sudanese community, for example, might go to an outing, but only with other 
members of the Sudanese community. That was an issue within a lot of communities, they always ask why we can't all just go together and share the day together.

Another issue that I found often is that when migrants first come to Australia, they are often spoken to by people who have maybe a conservation background or people who work in the department of environment for example, or even just by people in the mainstream population. And these people seem to have the idea that migrants who come here might not have an understanding of the environment. Maybe they don't know the green and the yellow for Australia's colours (but Brazil also has green and yellow!) but they do have an understanding of the environment in a lot of different ways. Sometimes I don't think that's respected.

So I made the workshops very participatory. It was very valuable to have run that one hour workshop beforehand, because inside the classroom or inside a neighbourhood centre, I could engage with people much more than maybe I would be able to do later on, outside when I was doing the field trip running around and all that. So the workshops gave people an opportunity to explain how they felt about the new environment and to explain the differences between coming from say rural Africa to Sydney, or from wherever they were from to this new environment. That meant that people DID have the chance to talk about what THEY thought about nature and the environment, maybe where they come from or maybe the environment here. So from the very beginning we showed that we respected what they already know about the environment.

Then it's very important, in my view as that first step to familiarise people with their new environment. And that's a word that I like to use because that word familiarise is also used in areas such as counselling, it's often that same sort of familiarisation. For example, a plant is a classic example to explain things that were edible if that's how they did things where they came from. So it's that idea that by re-creating a little bit of what you come from, you can become familiar like that with new things. So to take a step like that, people understand small things like, you know, learning about a gum tree. Small things like might be seen as small things, but that is a step to familiarise them with their new environment. 
I found that very important in the process of so-called 'settlement'. So where this is hopefully going to lead to is to contribute more into the settlement side, to be using environment to help people to settle to Australia. When a migrant first comes here, they go and see the Taxation office, they go and see Centrelink, they have all that as part of their 'settlement', but maybe the natural environment all around them gets put aside, or even the relationship with the people in the region here. So that's an area I'm very interested to use such a program in the settlement process, to make people a little bit more familiar with the environment, to help them feel a little bit more at home here.

I had a client, for example, a Sudanese woman who had never leave the town centre of Auburn. If you've ever been to Auburn, I mean not the whole council area, but just that little strip there near the shops. In five years she had never left that area. I took her to Olympic Park and did a walk around the Mangroves there. And she was absolutely gob smacked - but this is literally only ten minutes away from where she has been. So this program also has an element of people becoming able to move around comfortably.

Another way this program could help with this familiarisation was with the Karen, the minority group in Burma.

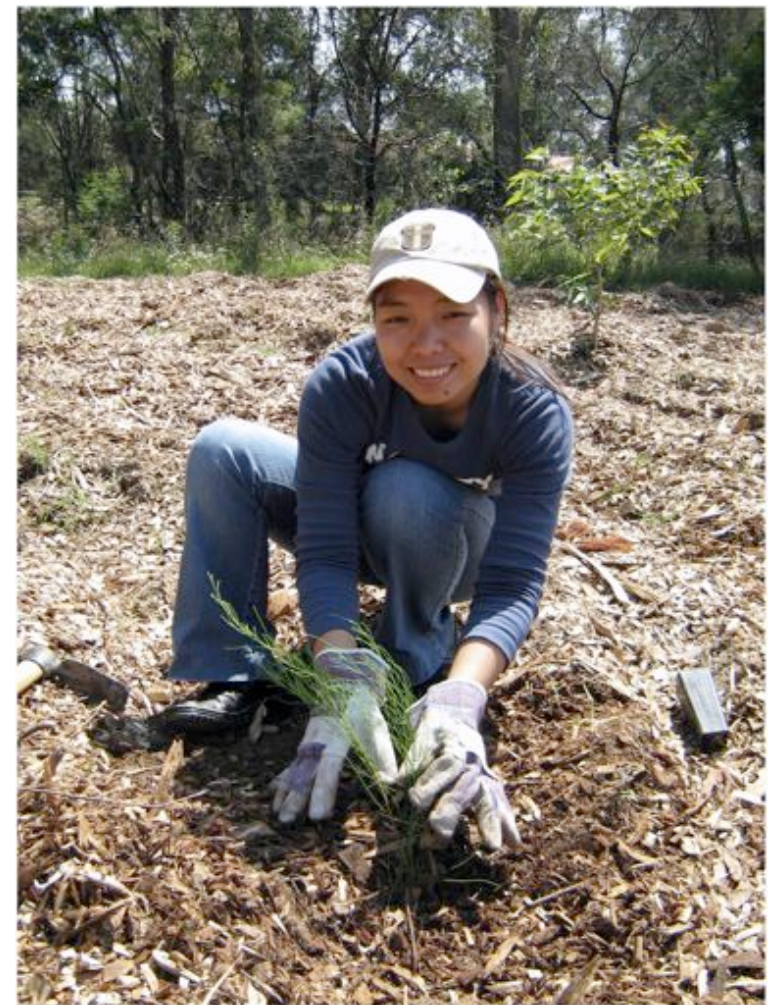

A young member of the Karen community planting a tree during the Operation Bluetongue outing. 
As the members of this group told me, they believe that when you plant a tree you immediately have a connection with that place. So we had an outing with 60 Karen and all of them had the opportunity to plant a tree.

The simple act of planting a tree - as one of that group of trees the people planted meant a lot to all of them. And as one Karen man explained to me, it meant even more for him because both his son and his father were able to be there when the trees were planted. He actually became quite emotional about it during the outing because he felt that all three generations of his family had been able to build their connections together through that experience.

So this program meant we could introduce concepts about the web of life - about our connection, our relationship to everything. We did it in a very basic way, with very basic English. But that is what the program was able to do. As one person said who took part in the program:

It made me think about the importance of (the) environment. It's our responsibility to keep good habits and to keep a good web of life. (Anonymous, NSW Adult Migrant English Service, Surry Hills)

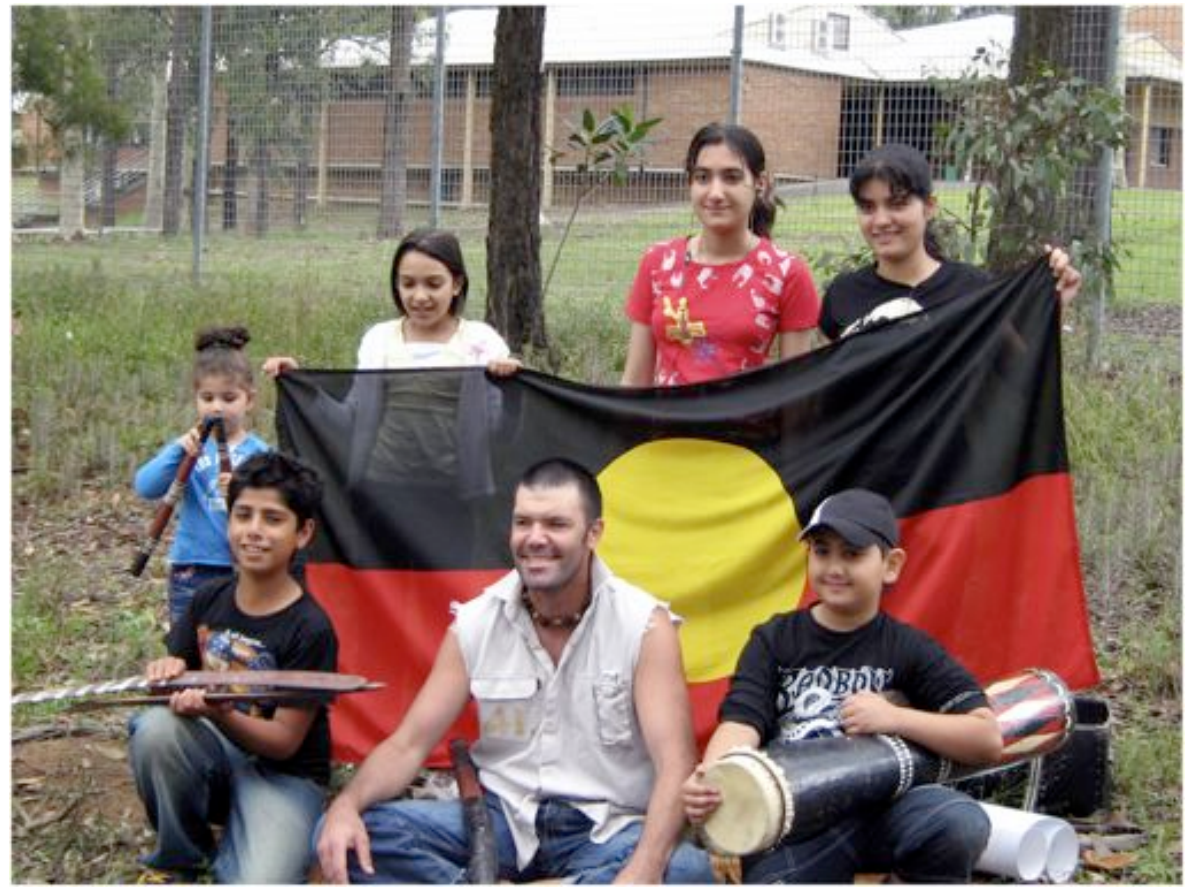

Iraqi Minority group (Mandaeans) learning about Aboriginal Culture during an Operation Bluetongue outing. 


\section{Questions}

\section{Question 1:}

You said that there's different cultural groups that view the environment in different ways or they interpret it differently, how do you know which value the group think is important, before you take them out there? How do you know what to present to that group so they gain maximum relationship with the environment? Do you do research beforehand? You talked about how a tree is an emotional connection for them, and there must be other things in the environment that connect people with nature. How do you find them?

\section{Leandro:}

It is not possible to do a great amount of research beforehand, because in this program, there are many different people and groups. But because the workshops are participatory, as you engage with people, they talk and mention things like that. I came with a set idea about what I was going to presenting in my workshop. But obviously that changed. I had an educational frame for it, because I had to approach a lot of schools that teach migrants. So the workshop plan had to have an educational structure, but if I had come with what I thought would be an understanding of their values, it would more likely have turned out to be my values, rather than their values. So for me it's a very important matter to open up that space for them to say what their values are about the environment. So I have no knowledge about specific values. And anyway, it was almost impossible because I took a group out with twenty five different language groups. You know, if I had fifty people, there might be twenty five different language groups in that group, in itself. So each one of them would have their own understanding, their own views of the environment. So it's very, it's very hard - so I never came with any preconceived understanding of what their values were.

\section{Question 2:}

After a while did you know which aspect of the environment to show?

\section{Leandro:}

You do get to understand different groups differently, but again within that group, you know, people are all different - some are educated, some come from rural areas but 
some are from cities. Within, for example, a Chinese group that speaks Mandarin, you know some people might have come from Hong Kong, another person might come from rural China, so they will each have a whole different way that they see the environment. So I guess for me it was mainly just gauging it from conversations and through feedback and evaluations but even that gives me a only a very loose kind of idea what their values are.

\section{Question 3}

It's a fantastic program. Are you going to take it and push it to another government body or look for somebody to fund it?

\section{Leandro:}

At the moment, we've put an application to actually run this, believe or not, through the department of immigration. And they're very, they're very keen, but although we put an application in, we just have to wait. But it will part of the process of settlement, because the immigration runs settlement programs and this is what this is. I don't know how they'll go about it, if each migrant resource centre would take it and apply for a small grant to take people to various different place. But that's what we're aiming to go more towards, more to addressing that strong social side rather than apply again for the department of environment and climate change.

The outcomes have been fantastic but I haven't been able to publicise it widely because it was such a low budget program. I did put a learning kit together mainly for people who work for a migrant resource centre, for example, who might already have a lot of experience with migrants, so they know their needs, they know some of their values. But they have very little understanding about the environment, so this is an opportunity for them to just maybe get some ideas or contact people or organisations who might assist them with that information. And also the learning kit is for council workers who work with the environment but have no idea how to approach or work with migrants. They tend to use a lot of difficult words, for example, and things like that. So I put a kit together, with a booklet and a CD. And we are all keeping our fingers crossed that some new funding comes through. 